\title{
Studies on China's Fiscal Policy to Support the Supply-side Reform
}

\author{
Feifei $\operatorname{Han}^{1, a}$ \\ 'Department of Economic Management, School of North China Electric Power University, Baoding \\ 071003, China \\ ahff869803@163.com
}

\section{Keyword: Fiscal policy; Support; China’s supply-side reform}

\begin{abstract}
Carrying out and advancing the supply-side reform is an important strategic arrangement, for China's adapting and leading the new normal economic development and promoting long-term sustainable economic development. As not only the core of supply-side reform, but also an important means of macroeconomic regulation and control, China's fiscal policy should exert the function of steady growth, as well as draw lessons from international experience, innovate and perfect the ideas and methods of regulation and control, and effectively support the supply-side structural reforms by encouraging scientific and technological innovation, reducing the tax burden on enterprises in a targeted manner, accelerating the reform of the social security system and strengthening government debt management, which are all based on the existing economic development Structural problems and contradictions,
\end{abstract}

\section{Introduction of China's Supply-side Reform}

On November 10, 2015, the concept of supply-side reform was first proposed at the Eleventh Meeting of China's Central Leading Group for Financial Leveraging. Then, the supply-side reform quickly became a "hot word" in China's economic field, repeatedly mentioned and emphasized by the Central Conferences and documents.

Supply and demand are concomitant concepts in economics. The Partial balance of supply and demand determines the micro-efficiency of the market, while the balance of total supply and demand determines the macroeconomic stability [1]. And there are two kinds of ideals to achieve the total balance between supply and demand as well as overall macro-stability of China's economy. On the one hand, we start from managing the total demand, called "demand-side management". On the other hand, we start from managing the total supply, called "supply-side management".

As we know, the total demand consists of consumption, investment, government purchases and net exports, which are determinants of short-term economic growth. Correspondingly, "demand-side management" is total quantity management, whose policy thinking focuses on stimulating the total demand to achieve counter-cyclical short-term growth, through government expenditure policies. While the total supply depends on capital, labor force, land, technical level and other elements, which are the determinants of long-term economic growth. Correspondingly, "supply-side management" focuses more on structural adjustment and aims to increase productivity and achieve economic growth in the long run, by optimizing the allocation of factors and optimizing the economic structure. Therefore, China's supply-side reform, which means the government begin to emphasizing "supply-side management" rather than the "demand-side management", faces two major changes, including change from the total stimulus to structural adjustment, as well as changes from short-term policies to medium-and-long-term reforms.

\section{The Present Situation of China's Fiscal Policy Supporting Supply-side Reform}

At present, China Ministry of Finance mainly affects supply-side reform from the following three aspects:

Fiscal Expenditure Policy. For one thing, the government influences the production factors and methods indirectly, and promotes the quality and efficiency of production, by promoting the development of public utilities such as education, science and technology. For another, the government supports and guides enterprises to reform the traditional industries, develop new industries and engage in basic research, through the financial special fund. 
Preferential Tax Policies. With the implement of tax cut and relief, the government reduces enterprises' production costs and guides them to develop key national industries, in order to achieve industrial restructuring and upgrading. Therefore, the impact of preferential tax policies on supply-side reform is direct and universal, and it helps to increase the accumulation of social capital in the long run.

State-owned Enterprise Investor Management. At present, some financial departments also assume the responsibilities of contributing to state-owned financial and cultural enterprises in addition to fulfilling their financial responsibilities [2]. On the one hand, the government enhances market competitiveness by directly injecting capital into state-owned enterprises, supporting essential projects including the transformation and upgrading of enterprises, as well as strategic mergers and acquisitions. On the other hand, the government promotes enterprises to become the real subject of market competition, by innovating the management system of state-owned enterprises and perfecting the corporate governance structure of enterprises, and then achieves state-owned enterprises' self-management, self-financing, self-restraint and self-development in accordance with the requirements of the modern enterprise system, while obtaining state-owned capital operating income.

\section{The Problems China Ministry of Finance Faced in Supporting Supply-side Reform}

Fiscal Revenue Tension and Difficult Balance of Financial Revenue and Expenditure. As China's economy growth has shifted from high-speed to medium-high-speed, the pressure to balance the financial revenue and expenditure has been further highlighted [3]. Firstly, the revenue growth slowed down. In 2015, China's general public budget revenue grew by $5.8 \%$, reducing $2.8 \%$ from the same period of last year, and was $1.5 \%$ lower than the budgets of the beginning of the year, due to the slowdown in economy growth rate, falling prices and declining efficiency. Secondly, the sluggish real estate market and other factors led to the national government fund income dropped sharply $15.9 \%$. So the fiscal revenue situation will become even more severe, affected by the potential decline in growth rate of fiscal revenue, the tax cuts of transformation from business tax to value-added tax. Thirdly, the trend of rigid growth in government financial expenditure will not change. There are still many problems such as too much special finance funds distributing too messy, inadequate utilization of fiscal funds in an integrated manner, and low efficiency in the use of fiscal funds, and so on.

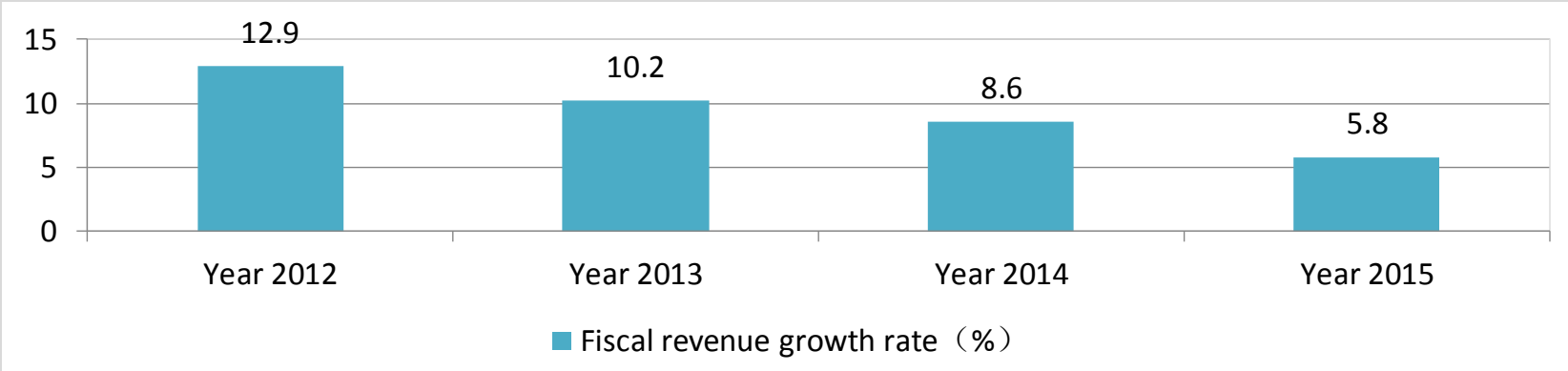

Figure 1. China's fiscal revenue growth rate in year 2012-2015

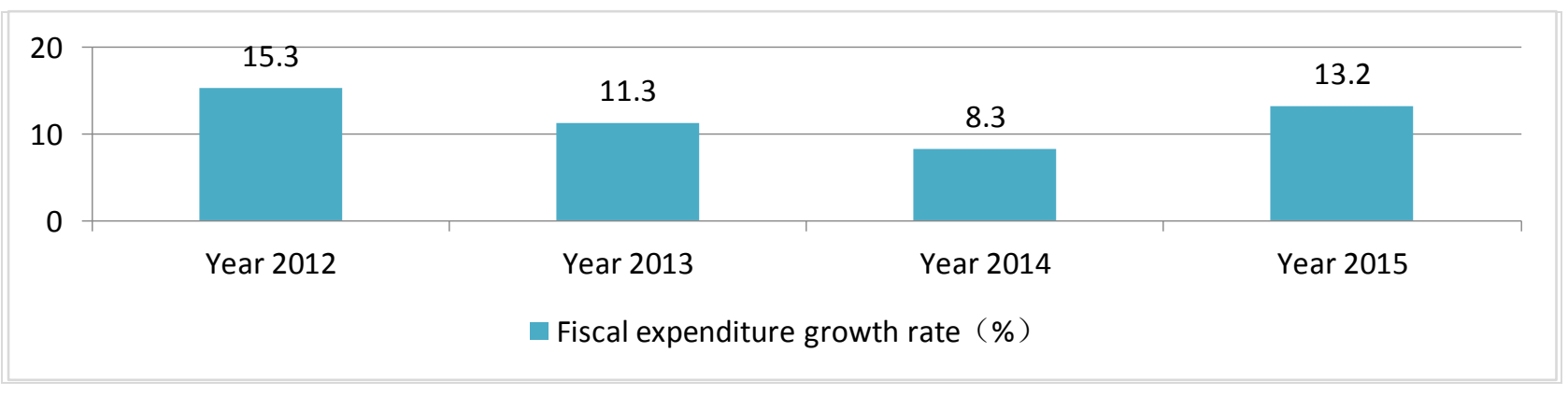

Figure 2. China's fiscal expenditure growth rate in year 2012-2015 
Potential Financial Risks Cannot Be Ignored. At present, the basic framework of local government debt management in China has been established, and the local government's debt financing mechanism is more standardized. However, it still takes time to solve the problems left over by history, and hidden financial risks remain. Firstly, the debt ratio of some municipal and county governments is relatively high, whose repayment of debt and interest is under greater pressure, under the background of a substantial drop in land transfer income. In addition, some regions have the possibility of regional risks. Secondly, the local government may have a heavy debt burden. As for them, there is a great risk that they should deal with some debt related a wide range of issues and complicated situations. Thirdly, risks arising from some financing platforms or uncertainties in contingent debt may be transmitted to the financial system, and then aggravate the risk of in local finance.

Problem of Social Security Fund Gap Haven't Be Solved. Although the current social security premium reduction is imminent, but the basic problem of social security fund gap hasn't been solved, yet. The reform of our basic pension insurance starting late, the institutional mechanisms being not perfect, the lack of original pension accumulation, coupled with the accelerated aging of the population, the increase of pension benefits and so on, all these factors result in the pension gap's growing. According to statistics, at the end of 2014, the "empty accounts" of personal accounts for endowment insurance for urban workers in our country reached about 1 trillion yuan. More than two-thirds of the national basic and endowment insurance funds for urban and rural residents come from financial subsidies, while individual contributions are less than $30 \%$. With the contradictions between fiscal revenue and expenditure increasing, this mode of social security fund operation is unsustainable, obviously. That's to say, the space and the effect of the active fiscal policy will be constrained, if these problems cannot be effectively solved.

\section{Reasons for Problems Exist in Supply-side Reform.}

Judging from the current situation of various industries, the most serious problem in China's economy is the lack of effective supply and the excess of ineffective supply [4]. On the one hand, the basic material of production in the middle and upper reaches of the industry, as well as the supply of traditional low-end consumer goods are seriously over-supplied. In the area of production material, the main industries are overcapacity, such as steelmaking, iron making and cement, and so on. While in the field of consumer products, the supply system, for the low-income groups in the past, simply imitated the foreign products, whose added value is low. On the other hand, high-performance products, high-quality consumer goods and public goods and services are under-supplied. In the field of industrial products, most industries are still in the relatively low-end stage of "import and install", with a serious shortage of core technical reserves. In the field of consumer goods, the middle and upper income groups in our country have been expanding constantly. Some of these groups have strong purchasing power and desire to buy. But at present, China's product supply system cannot meet their actual consumption needs, and the insufficient effective supply leads to the exuberant real demand being severely suppressed, which perform as "reserve money to purchase", or being met by overseas purchases, resulting in "demand spillover".

\section{Suggestions on China's Fiscal Policy to Support Supply-side Reform}

China's fiscal policy to support supply-side reform has both opportunities and challenges. China Ministry of Finance should not only deepen the study of the supply-side reform macroscopically and hold the overall situation, but also grasp the entry point of the policy from a microcosmically, and follow the following ideas and measures, in order to promote supply-side reform.

Improve Preferential Tax Policies to Provide a Fair Environment for the Supply-side Reform. Tax deductions or duty free can reduce enterprises' research and develop costs, as well as production costs. In view of the characteristics of new industries' large investment in the early stage, their pre-research and development costs should be included into pre-tax deductions. Thus, the costs of enterprises can be effectively reduced. Enterprises incorporated into the scope of emerging industries may enjoy the tax reduction and exemption policy within a certain period of time from the date of their 
establishment. The government can guide enterprises to deepen the supply-side reform effectively through the preferential tax policies, which are more convenient than the financial support for the fund to benefit all state-owned enterprises and private enterprises, providing a fair environment for the supply-side reform.

Improve the Financial Support to Promote the Upgrading of Traditional Industries. Supply-side reform should deal with the development of traditional industries, helping enterprises to resolve excess production capacity, encouraging enterprises to tap the domestic market, expand the international market and digest their inventory products [5]. At the same time, it is necessary to support upgrading traditional industries, increasing investment in application of new technologies, promoting the transformation of scientific and technological achievements, and fundamentally helping traditional industries and enterprises to get out of their original predicament.

Increase Financial Investment in Supply-side Reform to Guide the Development of New Industries. Emerging industries have the characteristics of high technology content, high added value of products, green environmental protection and strong employment absorption ability, which are the breakthroughs to enhance the quality of China's economic growth and represent the future direction of industrial development. However, some newly-started industries have large investment in the early stage and have difficulties in developing their own strength. So they need financial support from the financial departments. Therefore, the financial departments can play the leverage function of the fiscal funds, through offering special fiscal funds for industrial development as well as guiding social capital investment.

Strengthen Government Debt Management to Reduce Risk and "Crowding-out Effect". The subject of supply-side reform is enterprises, but the government provide supply-side public goods. As we all know, the issuance of government bonds is an important means by which local governments raise funds for public projects [6]. However, excessive government debt will accumulate financial risk, at the same time will have a "crowding-out effect" on social investment. Government debt issuance will cause changes in the relative level between the interest rate of government bonds and other securities, resulting in the substitution effect of government bonds on other securities and the reduction of demand for other securities, lowering the overall level of capital formation. In the process of debt issuance to raise fund for public products providing and tax cuts, the government should control the debt scale properly, strengthen the management of debt balance, and actively reduce the debt risk, as well as minimize the "crowding out effect" of social investment.

\section{References}

[1] J. Cui and Y.X. Zhang. The Connotation, Motivation and Financial Policy of Supply-side Reform [J] .Fiscal Supervision, 2016, (09): 12-14. (In Chinese)

[2] C. Meng. Financial Policies Supporting Supply-side Reform [J] .Henan Social Sciences, 2016, (01): 10-11. (In Chinese)

[3] T.P. Lian. Study on the Issues of Fiscal Policy Effectively Supporting Supply-Side Reform [J]. Southwest Finance, 2016, (07): 68-71. (In Chinese)

[4] J. Lv and H.X. Han. Research on Fiscal Policy to Promote Supply-side Structural Reform [J] .Research Journal of Economic Research, 2016, (59): 13-18. (In Chinese)

[5] Y. Shi. Study on the Ways and Countermeasures of Fiscal Policy to Promote Supply-side Reform [J]. Theory Research, 2016, (06): 90-95. (In Chinese)

[6] Z.W. Zhan. Policy Suggestions on Fiscal Promoting Supply-Side Structural Reform [J] .Journal of Finance, 2016,0 (05): 45-46. (In Chinese) 